\title{
PARAMETRIC INVESTIGATION OF ORIFICE ASPECT-RATIO ON LOW CURRENT HOLLOW CATHODE POWER CONSUMPTION
}

\author{
Matthew T. Domonkos* and Alec D. Gallimore ${ }^{\dagger}$ \\ Plasmadynamics and Electric Propulsion Laboratory (PEPL) \\ The University of Michigan \\ Ann Arbor, MI 48109 \\ Michael J. Patterson ${ }^{\ddagger}$ \\ NASA Lewis Research Center \\ Cleveland, $\mathrm{OH} 44135$
}

\begin{abstract}
As part of an effort to develop efficient hollow cathodes for the International Space Station and low power electric propulsion systems, the effects of orifice length-to-diameter aspect-ratio on the performance of 0.5 to $2 \mathrm{~A}$ hollow cathodes were examined to compare with previous experiments and a recently developed model. Cathodes were constructed with nominally identical orifice diameters and lengths that varied from 1 to 6 diameters. The performance of the cathodes was evaluated at the beginning of life and after at least 50 hours of operation. The data generally followed the trends predicted by the model with a few exceptions which appear to be related to the thermal environment of the cathode. Power consumption scaled with the orifice aspect-ratio, while the minimum spot mode flow rate was inversely related to the length-to-diameter ratio. At currents below $1.0 \mathrm{~A}$, the cathode operation became more complex than that which is assumed in the orifice model; low operating temperature caused instabilities in several of the devices.
\end{abstract}

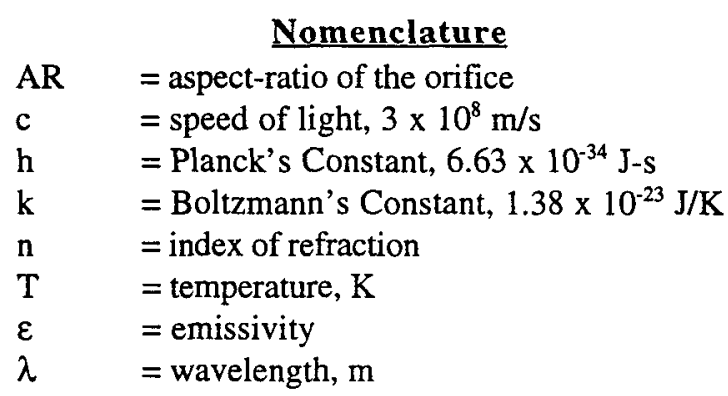

\section{Introduction}

A parametric investigation has been conducted at the NASA Lewis Research Center in order to evaluate the effect of orifice aspect-ratio on the performance of low current hollow cathodes. The aspect-ratio is defined as the orifice length divided by its diameter. The NSTAR derivative ion thruster for the Deep Space 4 mission, the plasma contactor for the International Space Station, and the NASA Lewis $8 \mathrm{~cm}$ ion thruster program all have requirements for low flow rate, low power cathodes. ${ }^{1,2}$ Experimental data ${ }^{3,4}$ exist both to support and to refute the hypothesis that cathode performance is inversely proportional to the orifice aspect-ratio. A recent hollow cathode model developed by Mandell and $\mathrm{Katz}^{5}$ describes the physics leading to the conclusion that cathode performance scales inversely with orifice aspect-ratio. Ions entering a finite length orifice will undergo collisions as they traverse the channel. Ions lost to collisions with the walls must be balanced by ions created in the orifice in order to satisfy the condition of a quasineutral plasma at the exit of the orifice. As orifice aspect-ratio increases, the number of ionizations occurring increases, and the conductivity of the plasma in the orifice decreases. The energy transport within the orifice also varies inversely with the aspect-ratio, and modeling the orifice processes becomes increasingly important to making an accurate prediction about the performance of the cathode. The physical arguments for the importance of orifice aspect-ratio to cathode performance are sufficiently compelling to warrant a new evaluation of the experimentally observed effects, particularly when trying to minimize the power consumption during low current operation. This report summarizes the experimental findings concerning the impact of

\footnotetext{
* Graduate Student Researcher, Student Member AIAA

t Associate Professor, Senior Member AIAA

₹ Research Engineer, Member AIAA

Copyright $\odot 1998$ by Matthew T. Domonkos. Published

by the American Institute of Aeronautics and Astronautics,

Inc. with permission.
} 
orifice aspect-ratio on the power consumption of low current hollow cathodes.

Although the current density in the orifice far exceeds that found anywhere else in a plasma contactor, ion thruster, or Hall thruster, previous modeling efforts ${ }^{6,7}$ have ignored the effects of the orifice processes on the overall performance. Mandell and $\mathrm{Katz}^{5}$ have proposed a model which conserves both energy and ions necessary for quasineutrality. The model assumes the plasma properties at the entrance to the orifice are known. The ion loss to the walls of the orifice is balanced by electron-neutral collisional ionization. The Ohmic heating in the plasma is balanced by the ionization, radiative, and convective losses. With the orifice region taken as a control volume, the flux of ions incident at the entrance will either collide with the walls or be transmitted through the orifice. Since ion-wall collisions represent a loss in the energy balance, optimization of power consumption requires minimization of the orifice aspect-ratio. Typically in orificed hollow cathodes, the maximum required current determines the orifice diameter. ${ }^{8}$ While the theoretical picture indicates that orifice length should then be minimized, practical considerations force a finite length orifice. The machining and welding methods currently employed to fabricate the cathode tubes require a certain minimum overall thickness of the orifice plate. Rawlin and Kerslake ${ }^{9}$ were among the first investigators to observe the erosion of the orifice plates on hollow cathodes, and increasing the thickness of the orifice plate would, to first order, mitigate the problem of erosion. The goal of the investigation reported here was to provide experimental data for comparison with Mandell and Katz's ${ }^{5}$ model while meeting the practical considerations for cathode design.

This paper presents the results of a parametric experimental investigation of the effects of the orifice aspect-ratio on the power consumption of $3.2 \mathrm{~mm}$ diameter orificed hollow cathodes. The experimental apparatus and techniques are described first. Next, the performance data are presented. The results are then analyzed with an emphasis on the performance, and the implications for cathode lifetime are also discussed. Finally, the major conclusions of this investigation are summarized.

\section{Experimental Apparatus}

Four $3.2 \mathrm{~mm}$ outer-diameter hollow cathodes with different orifice aspect-ratios were assembled as shown in Figure 1. The construction of the hollow cathodes closely followed the methods developed previously at the NASA Lewis Research Center. ${ }^{10,11}$ The orifice plates were machined on a lathe. Figure 2 illustrates the variation in the aspect-ratios for three of the cathodes tested. Although some dimensions of this schematic were exaggerated for clarity, the orifice plate dimensions, the cathode-keeper gap $\left(\mathrm{L}_{\mathrm{ck}}\right)$, and the keeper orifice diameter $\left(d_{k}\right)$ are all drawn to scale. For convenience, the cathodes are referred to in this paper as AR1, AR3, and AR6 for the orifices with aspect-ratios of 1,3 , and 6 , respectively. The fourth cathode had an orifice diameter forty percent smaller than the other cathodes and an aspect-ratio of approximately 3; it will be referred to as AR3' here. The orifice plates were electron beam welded to a refractory metal alloy tube with a $3.2 \mathrm{~mm}$ outer diameter. The electron emitter was a cylinder of sintered porous tungsten impregnated with $4 \mathrm{BaO}$ $\mathrm{CaO}-\mathrm{Al}_{2} \mathrm{O}_{3}$ and was located at the downstream end of the tube. The emitter outer diameter was nominally $0.38 \mathrm{~mm}$ smaller than the inner diameter of the tube.

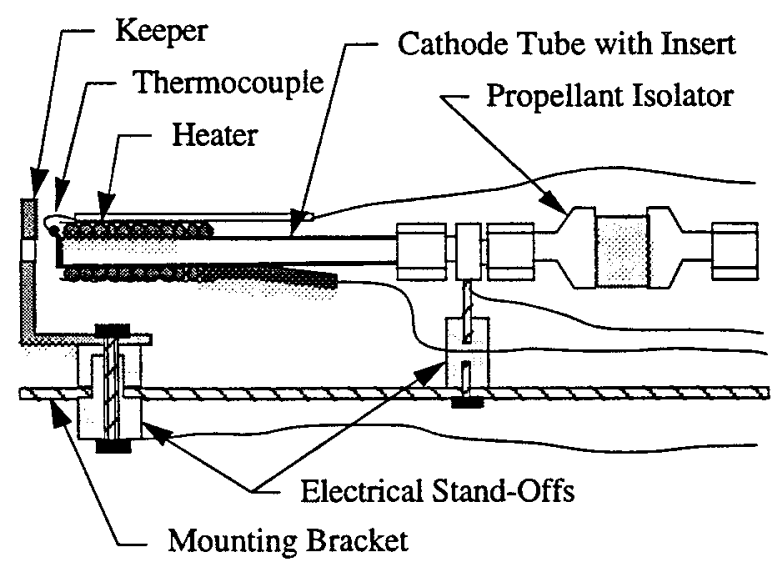

a) Schematic for the Hollow Cathode Assemblies

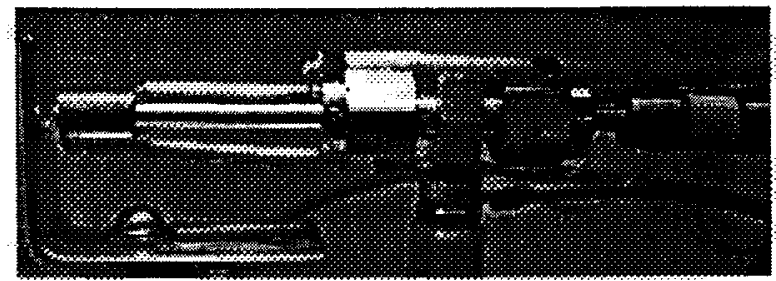

b) Photograph

Figure 1 - The Hollow Cathode Assembly

Refractory metal electrical leads attached to the upstream end of the emitter were swaged into electrical contact the with cathode tube. This also fixed the position of the emitter within the cathode 
tube. A sheathed heater was wound and friction fit to the end of the cathode tube. Metal foil was wrapped tightly around the outside of the heater to function as a radiation shield.

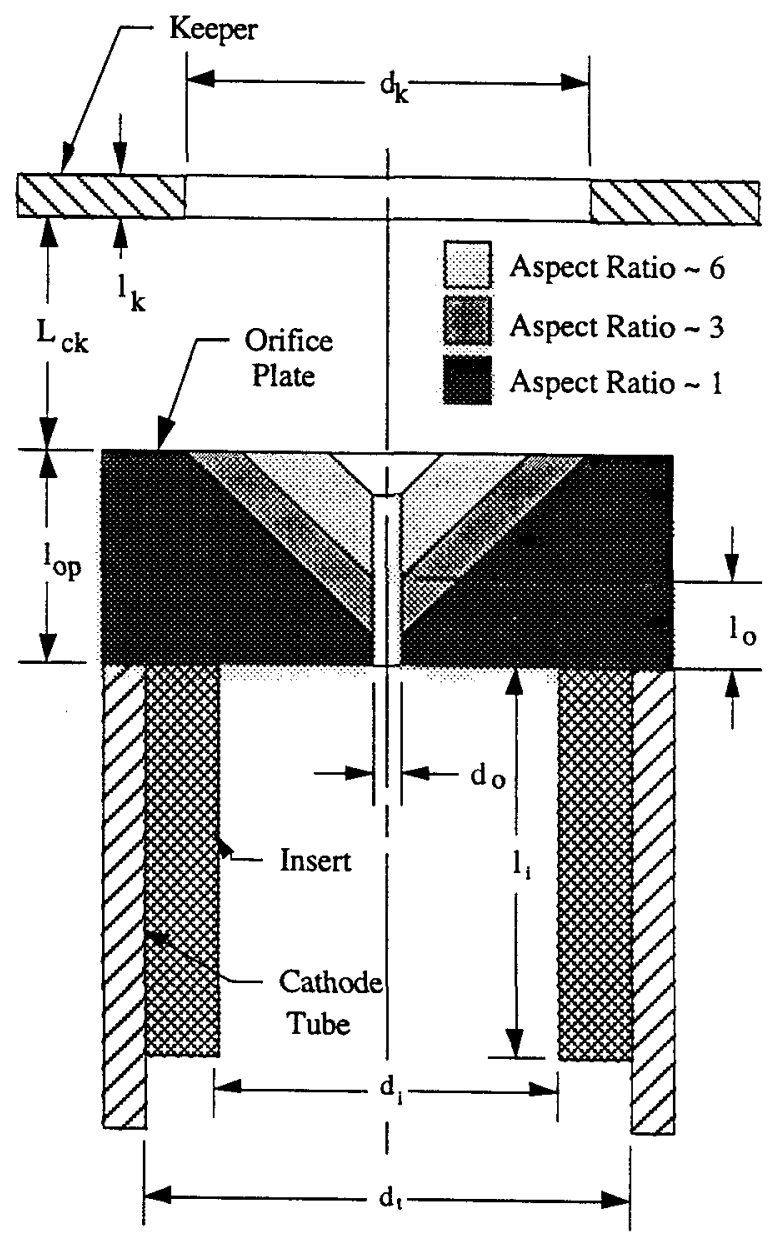

Figure 2 - Definition of Cathode Geometric Nomenclature

All the results reported here were obtained by operating a cathode-keeper discharge in the configuration shown in Figure 1. A ceramic propellant isolator was used to allow the cathode to float with respect to facility ground. The keeper consisted of a stainless steel tab with a hole on axis with the cathode tube. This provided a means for extracting a current, as would be required for use with a thruster, and permitted optical access to the orifice plate.

Research grade xenon (99.999\%) was supplied to the cathode via the expellant feed system illustrated in Figure 3. Electropolished stainless steel tubing 6.4 $\mathrm{mm}$ in outer diameter was used with ultra high vacuum metal gasket seals at all junctions. A capacitance manometer was used to quantify the leak rate after alterations to the feed system. The flow rate was calibrated using a bubble flow meter over the range from 0.5 to $5 \mathrm{sccm}$, and the error in the flow rate measurement was approximately constant at $\pm 0.07 \mathrm{sccm}$ over the range of flow. The delivery pressure of the regulator was set to $253 \mathrm{kPa}(22$ psig), and the flow rate was controlled using a needle valve, except for AR3 where a mass flow controller was used.

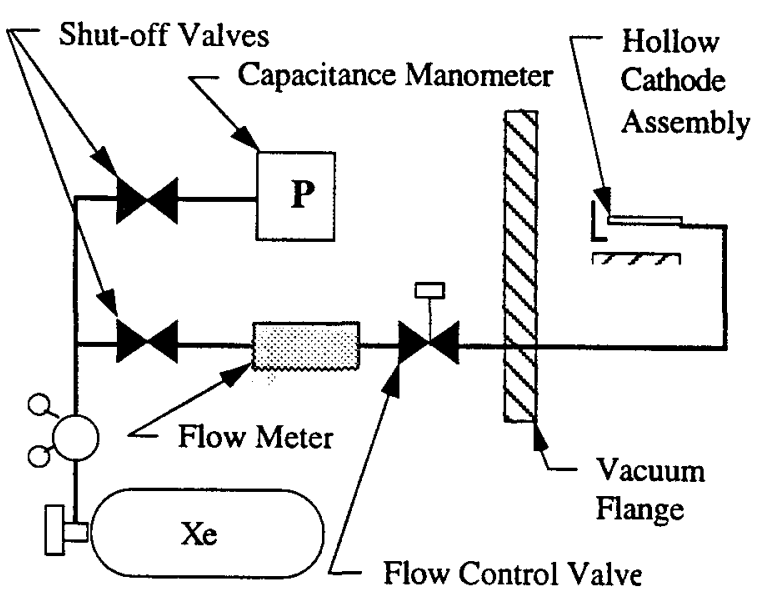

Figure 3 - Flow Schematic

Figure 4 summarizes the electrical circuit and instrumentation. The heater power supply was used for cathode conditioning and the preheat for ignition. The cathode-keeper discharge was initiated and maintained using a $3 \mathrm{~A}, 55 \mathrm{~V}$ DC power supply. Occasionally an in-line ignitor was required to start the discharge. The circuit permitted the removal of the ignitor power supply without interrupting the current. The cathode-keeper discharge was operated in current controlled mode. Both the discharge and heater currents were controlled by the computer data acquisition and control program. The computer recorded current, voltage, flow rate, temperature, and facility pressure data. The current and voltage measurements were calibrated with respect to digital multimeters with NIST traceable calibration. In the cases of AR1 and AR3, a Type R thermocouple was placed between the heater tip and the cathode tube as seen in Figure 1.

In addition to the thermocouple measurement, a disappearing filament optical pyrometer was used to measure the orifice plate temperature on AR1, AR3', and AR6. An emittance of 0.39 was initially estimated for these tests based on previous work. ${ }^{11}$ 


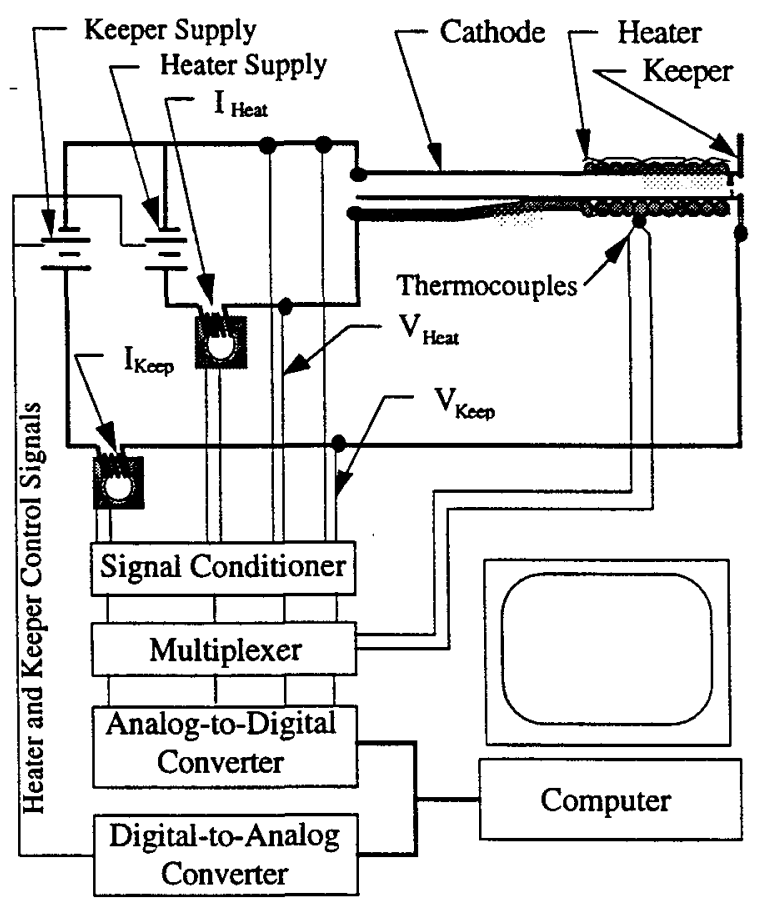

Figure 4 - Cathode Control and Diagnostic Scheme

indicate an emissivity as high as 0.525 depending upon temperature and composition. In addition, the transmittance of the $2.54 \mathrm{~cm}$ thick quartz window and the effect of the surface geometry of the orifice plate will determine the effective emittance at the pyrometer. Corrected temperatures for an emittance of 0.53 were also obtained from the pyrometer power supply. The data reported here represents the mean value, with the error bars extending to the limits of the estimated emittance. The definition of emissivity was used to calculate a temperature span for the optical thermometer. Wein's Law can be used to derive the following equation relating brightness temperature $\left(T_{\beta}\right)$ to the blackbody temperature $\left(T_{B B}\right)$ with a correction for emittance $(\varepsilon):^{13}$

$$
\frac{1}{T_{\beta}}=\frac{1}{T_{B B}}-\frac{\lambda n k}{h c} \ln \varepsilon
$$

where $\lambda$ is the wavelength transmitted by the red filter of the pyrometer, $n$ is the index of refraction, $k$ is Boltzmann's constant, $h$ is Planck's constant, and $c$ is the speed of light. Here the brightness temperature is defined as the temperature necessary for a blackbody to emit the observed radiation intensity, and the blackbody temperature, $T_{B B}$, is the true body temperature corrected for the emittance. Using Equation 1, the mean temperature between the limits of the emittance is reported here. By using the limits of the estimated emissivities, the accuracy of the optical thermometer temperature measurement was approximately \pm 1 percent.

These experiments were conducted in Port 2 of Tank 11 and Vacuum Facility 52 at the NASA Lewis Research Center. Port 2 is a $30 \mathrm{~cm}$ diameter by 30 cm long spoolpiece attached to Tank 11, and VF-52 is a $61 \mathrm{~cm}$ diameter by $90 \mathrm{~cm}$ long chamber. In both cases, a $25 \mathrm{~cm}$ diameter cryogenic vacuum pump was used to maintain a high vacuum in the port during testing, and the base pressure of Port 2 was approximately $7 \times 10^{-6} \mathrm{~Pa}\left(5 \times 10^{-8}\right.$ Torr $)$. The pump speed on Xe was approximately $1050 \mathrm{~L} / \mathrm{s}$, and operating pressures ranged from $2.7 \times 10^{-3}$ to $5.3 \times$ $10^{-3} \mathrm{~Pa}$ ( 2 to $4 \times 10^{-5}$ Torr). The pressure was measured using a Bayard-Alpert ion gage.

\section{Experimental Procedures}

Most of the experimental procedures described in this section were motivated by experience with the Space Station Plasma Contactor program. ${ }^{10,11}$ Using essentially the same methods was the best possible means to achieve similar lifetimes and provide continuity to the hollow cathode research effort at the NASA Lewis Research Center.

\section{Feed System Bake-Out}

After any modifications to the feed system where internal surfaces were exposed to the atmosphere, such as Xe bottle replacement, the feed system was baked-out at vacuum. The goal of this procedure was to expel most of the contaminants that adhere to the feed system surfaces. First the system was evacuated to high vacuum for at least 12 hours. Heater tape, wound about the feed system tubes and fittings, was then activated for a minimum of 24 hours. The feed system was allowed to return to room temperature before continuing.

\section{Feed System Evaluation}

After the bake-out, the leak rate of the feed system was determined to verify feed system integrity. This was done by closing the feed system to vacuum and monitoring the pressure and temperature of the system for at least 24 hours. With an estimate of the feed system volume, the leak rate was determined and compared with the pass/fail criterion developed for space station plasma contactors. ${ }^{10}$ For the tests reported here, this procedure was only performed after Xe bottle replacement. 


\section{Feed System Purge}

Prior to cathode activation the feed system from the flow control valve through the cathode was evacuated to high vacuum for at least 12 hours. Using this procedure, the contaminants from the feed-system interior were removed at ambient temperature when they are less likely to react with the cathode surfaces.

\section{Cathode Activation}

The cathodes were activated according to procedures developed previously" following any exposure of the cathode to atmosphere. After activation, only a short preheat of the cathode was necessary prior to ignition.

\section{Performance Evaluations}

The cathode performance was determined by measuring the discharge voltage once a quasiequilibrium was reach for a given flow rate and current. The cathodes appeared to reach a quasiequilibrium after approximately 15 minutes, so that the data taken were assumed to be representative of an equilibrium point. The term "quasi-equilibrium" is used here to emphasize that the operational state of the cathodes varies slowly over their lifetime. Figure 5 illustrates the performance evaluation procedure. Typically the flow rate was set to a nominal value initially, brought incrementally through a preset range of flows until plume mode operation was induced at low flow rate. The cathode was then brought back to the nominal flow rate before the current was changed.

\section{Performance}

\section{Results}

In optimizing the performance of a hollow cathode, the goals are to minimize power consumption and mass flow rate while maximizing lifetime. In the cathode-keeper discharge, power and voltage are related by definition. Consequently, the variation of voltage as a function of the flow rate, which is summarized in Figure 6 for the devices tested in this investigation, has been used extensively to represent the performance of the cathode. Results for AR3' are only shown at $0.75 \mathrm{~A}$ because of the limited current range of this device; at $1.0 \mathrm{~A}$, the orifice plate temperature exceeded that required for extended life. ${ }^{3}$ Cathode AR1 initially operated at the lowest voltage, but also required the highest flow rate to maintain spot mode emission. At 50 hours, the spot-modevoltage of AR1 was comparable to that of AR6 after it had run for 140 hours. The relatively large increase in operating voltage experienced by AR1 appears to

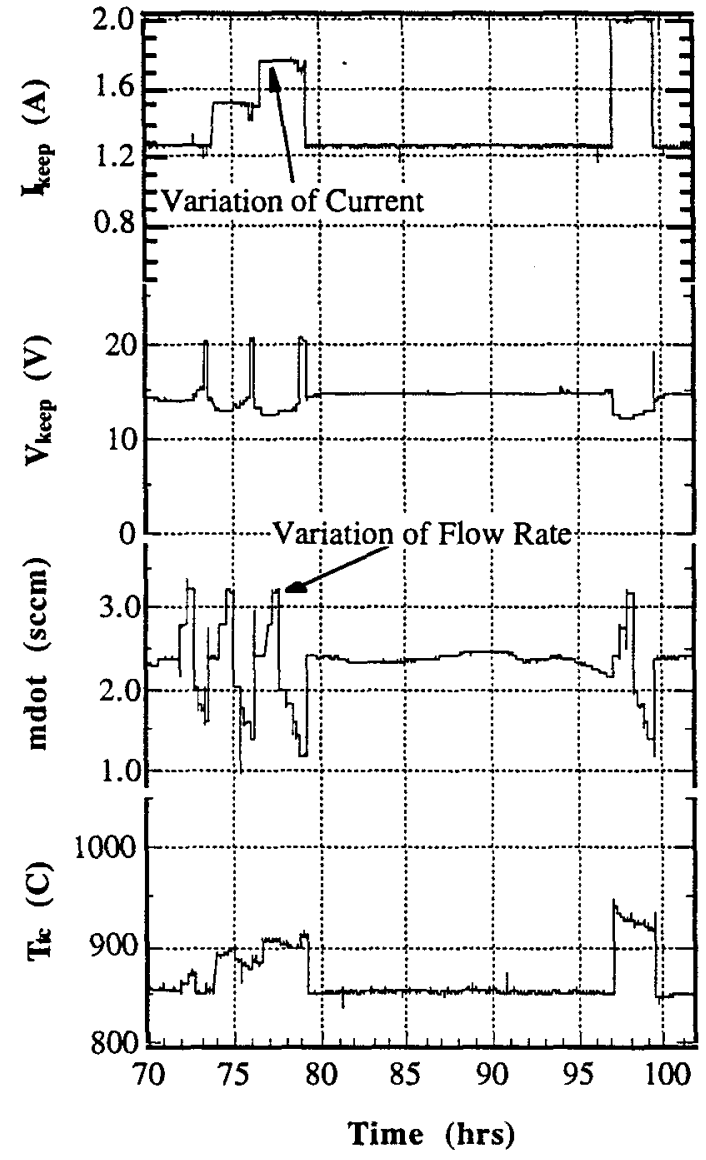

Figure 5 - Performance Characterization Procedure

be an effect of operation at low temperature. As will be shown later, ARl operated below $800^{\circ} \mathrm{C}$ at 0.75 $\mathrm{A}$, and at this temperature, insert chemistry can induce unstable operation. ${ }^{3}$ Although AR3 was only run for a limited time for this investigation, its initial characteristics can be compared with those from the other cathodes. At $0.75 \mathrm{~A}, \mathrm{AR} 3$ transitions to plume mode between 1.8 and $2.0 \mathrm{sccm}$, and has a spot mode voltage greater than any of the other cathodes initially. Cathode AR6 showed a smaller rise in discharge voltage over a longer period of time than AR1. In addition, the flow rate for transition from spot to plume mode increased with time. Post-test analysis of the orifice plate indicated that the diameter increased by approximately 50 percent, which accounts for the proportional change in the transition flow rate. As stated previously, the orifice diameter of AR3' was 60 percent that of the other cathodes, and the transition flow rate appears to scale 

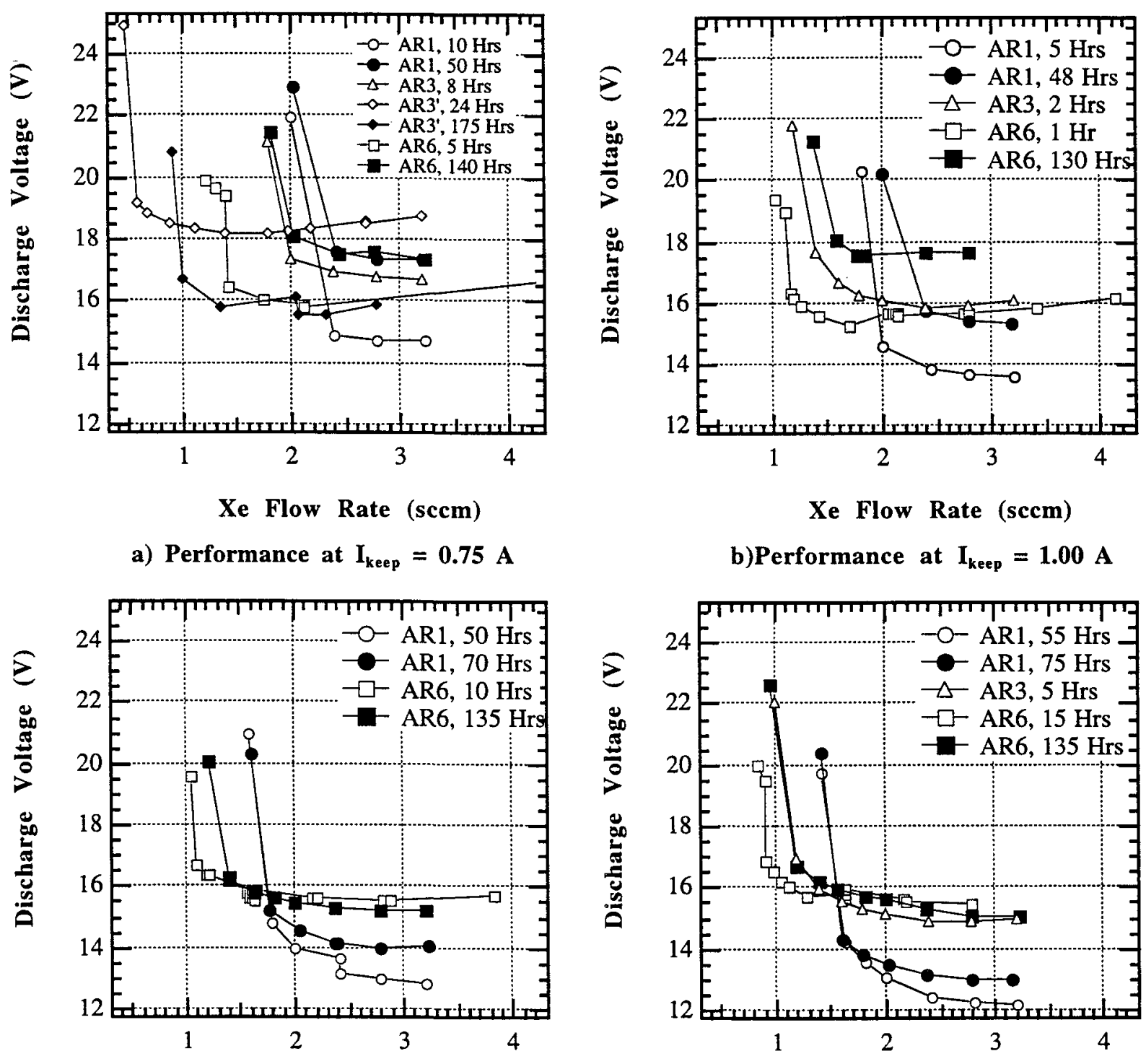
Xe Flow Rate (sccm)
c) Performance at $I_{\text {keep }}=1.25 \mathrm{~A}$

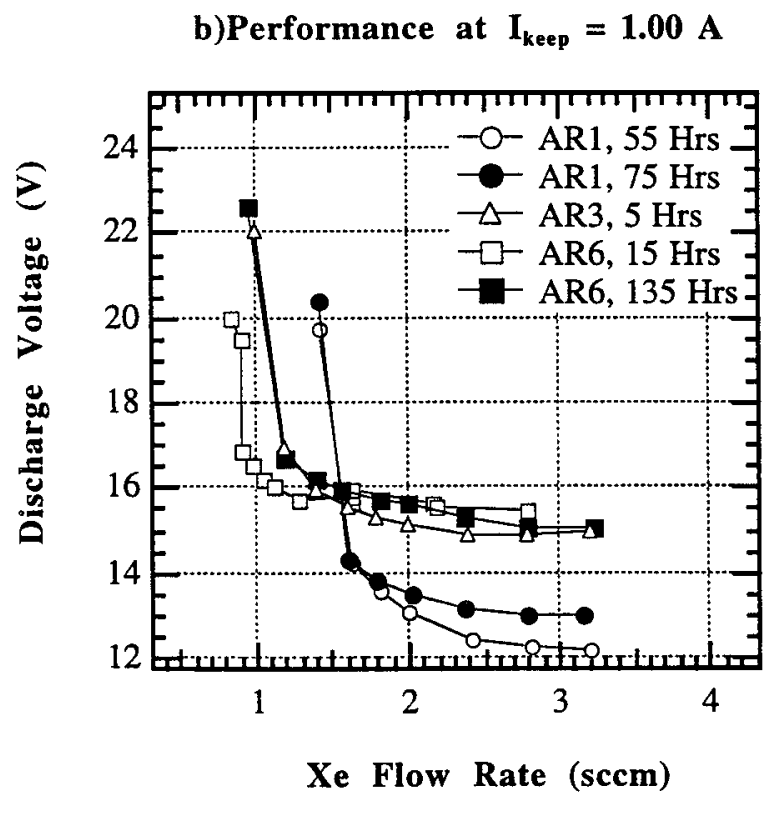

b) Performance at $I_{\text {keep }}=1.50 \mathrm{~A}$

Figure 6 - Performance Characterizations of the Hollow Cathodes

time. The transition flow rate also increased with time. These two observations suggest an increase in orifice diameter, although post-test measurements were not performed on this cathode.

As the current was increased, the variations in the performance characterizations as a function of operation time decreased (Figure 6b-d). At $1.00 \mathrm{~A}$, both AR1 and AR6 show similar shifts in the characteristics. At $1.25 \mathrm{~A}$ and $1.50 \mathrm{~A}$, the characteristics for AR1 show only a slight increase in the spot mode voltage with time. The reproducibility of the transition flow rates during the test is consistent with post-test analysis indicating that the orifice diameter had increased by less than 10 percent. At $1.50 \mathrm{~A}, \mathrm{AR} 3$ initially showed a transition flow rate and spot mode voltage between ARI and AR6 as expected. Cathode AR6 exhibited an increase in the flow rate required for spot mode at all currents, which was symptomatic of the increase in orifice diameter.

Cathode orifice plate temperature data were taken to assess the operating regime of the cathodes. Orifice plate operating temperatures also provide a measure of the power deposition within the orifice, and 
consequently, it was expected that the temperature would scale with aspect-ratio. Figure 7 shows the cathode orifice plate temperature as a function of flow rate. In all cases, the orifice plate temperature showed a weak dependence on flow rate. At a discharge current of $0.75 \mathrm{~A}$, the temperature data exhibit a high degree of scatter compared with data taken at higher currents. The scatter can be attributed to the fact that cathode stability is adversely affected at low temperatures. ${ }^{3}$ The orifice plate temperature for AR1 was only within the limits of the measurement at $2.00 \mathrm{sccm}$. Both AR3 and AR3' operated over approximately the same temperature range. Cathode AR6 initially operated hotter than all the other devices. However, the operating temperature of AR6 decreased over the next 140 hours until its operating temperature was essentially equal to AR3' at $0.75 \mathrm{~A}$.

Between 1.00 and $1.50 \mathrm{~A}$, the temperature profiles appeared more regular, and the monotonic decrease in the temperature with decreasing flow rate until the onset of plume mode was seen in most of the cases. At 1.00 and $1.50 \mathrm{~A}$, the temperature profile for AR3 was between AR1 and AR6, indicating an intermediate level of power deposition. The change in the orifice plate temperatures of AR1 and AR6 over time was inconsistent; AR1 showed a slight increase in temperature at most conditions, while the temperature of AR6 decreased for all cases. The temperature decrease was yet more evidence of the increase in the orifice diameter.

\section{Discussion}

This investigation was initiated to evaluate the effects of varying the orifice aspect-ratio on the performance of hollow cathodes. The experiments were designed specifically to address apparently contradictory data about orifice geometry related phenomena. ${ }^{3,4}$ This section will compare the trends observed with those predicted by the orifice model of Mandell and $\mathrm{Katz}^{5}$ and examine the role that the operating temperature plays in the stability of the discharge.

\section{The Orifice Model}

The orifice model ${ }^{5,14}$ predicts that power consumption decreases with decreasing orifice aspect-ratio, and as Figure 8 illustrates, the experimental data approximately follow this trend. At low current, AR3 and AR3' required more power than AR6. Since these curves were calculated from the performance characterizations at the beginning of cathode life where AR6 operated at a significantly higher temperature than all the other cathodes, the relatively low power consumption of AR6 was likely a product of increased electron emission from the emitter at the elevated temperatures. At 0.75 A, AR3 operated more efficiently than AR3' which suggests that, for the same aspect-ratio, a larger diameter orifice consumes less power.

The minimization of the cathode power comes at the expense of additional xenon flow. The orifice model ${ }^{5.14}$ predicts a strong dependence of the flow rate at the onset of plume mode with the orifice diameter and a weaker dependence upon the length. Both of these trends are depicted in Figure 9. The orifice length was varied over a factor of approximately 6 , and the observed change in the transition flow rate spanned from 1.4 to $2.4 \mathrm{sccm}$ at $0.75 \mathrm{~A}$. The forty percent change in orifice diameter between AR3 $3^{\circ}$ and AR3 yielded a span from 0.6 to $2.0 \mathrm{sccm}$ for the transition flow rate. These results support the dependencies predict by the orifice model.

\section{Cathode Operating Temperature}

While the orifice model has demonstrated the capability to predict a number of trends in the operation of hollow cathodes, changes in orifice geometry with time were insufficient to account for all the observed changes in performance. The cathode AR1 experienced the largest change in performance with time of all the cathodes at 0.75 and $1.00 \mathrm{~A}$. The cathode AR1 also had the lowest orifice plate temperatures measured, which suggested that its emitter temperature was also the lowest. Mirtich and Kerslake ${ }^{3}$ showed that operation below $880^{\circ} \mathrm{C}$ on the insert leads to instability in the discharge and reduced lifetime. Given that AR1 exhibited instability in its operating point and operated at the lowest temperature of the cathodes test, the self-heating of AR1 was insufficient for extended operation at currents below 1.25 A. Consequently, stable operation of the cathode dictates the use of an aspect-ratio that provides sufficient cathode heating over the range of require currents.

\section{Conclusion}

The orifice model predicted most of the trends observed in this investigation. The flow rate required to maintain spot mode emission increased as the aspect-ratio or current decreased. Power consumption was observed to scale with increasing aspect-ratio and decreasing orifice diameter. While the power consumption was lowest for the orifice with an aspect-ratio of 1, this cathode exhibited some instability below $1.25 \mathrm{~A}$. Given the relatively short 


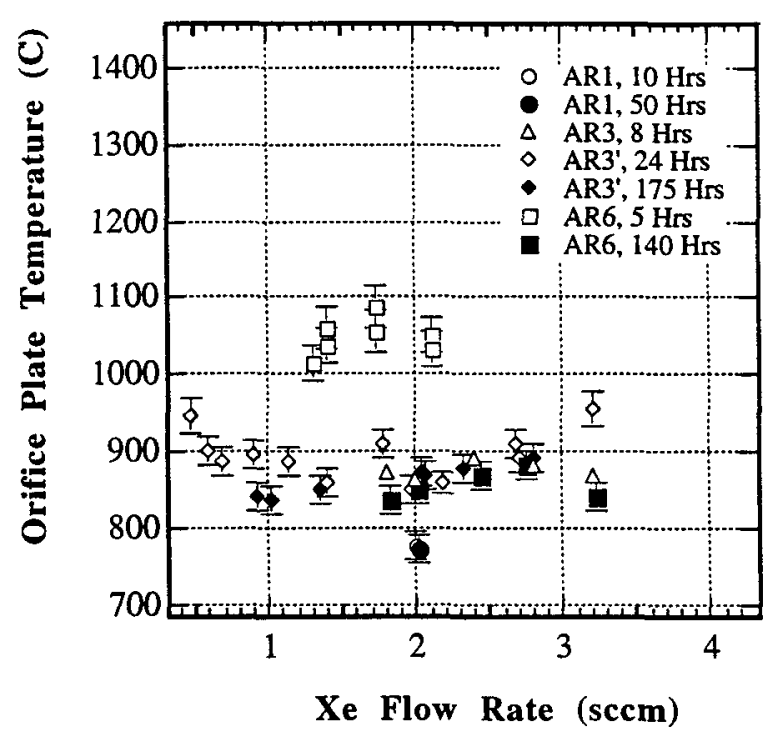

a) Temperatures at $I_{\text {keep }}=0.75 \mathrm{~A}$

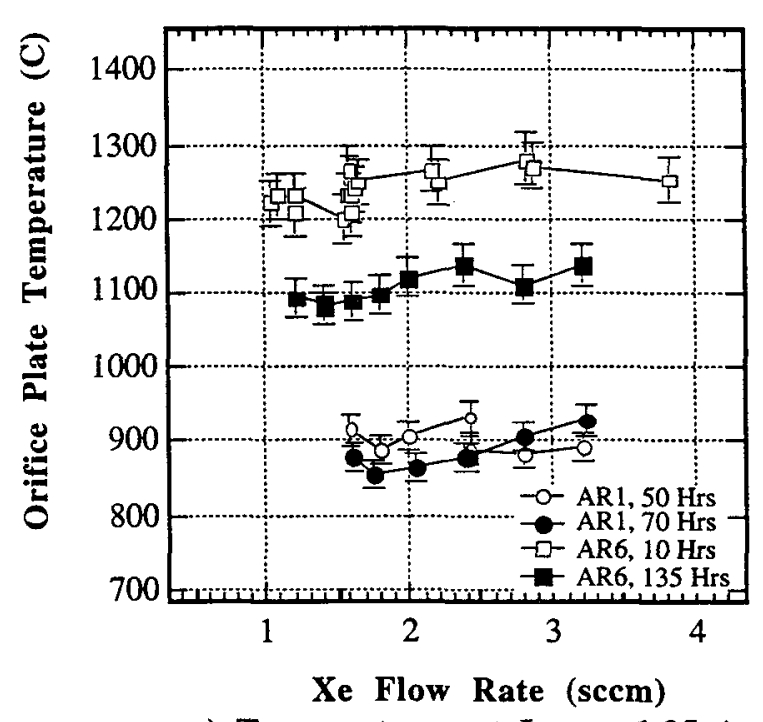

c) Temperatures at $I_{\text {keep }}=1.25 \mathrm{~A}$

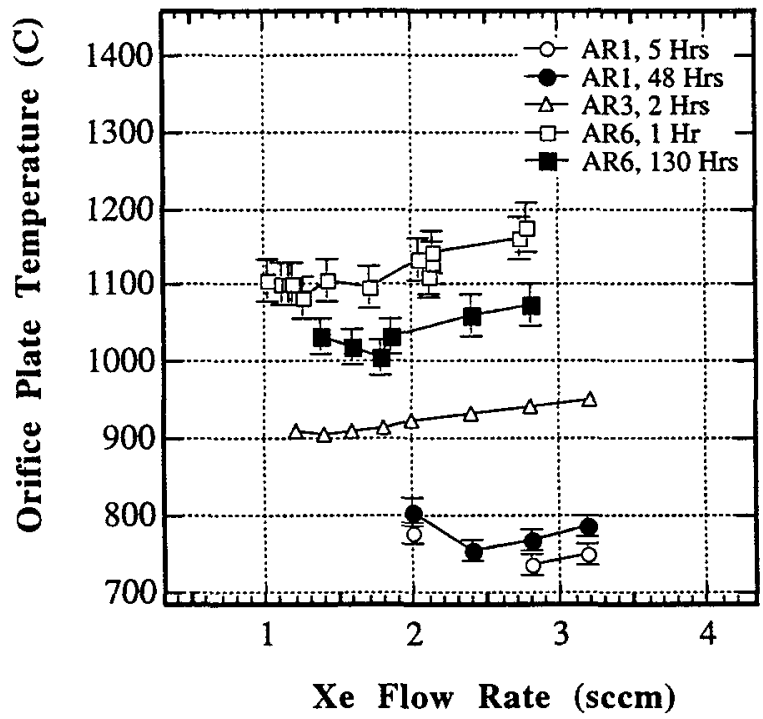

b) Temperatures at $I_{\text {keep }}=1.00 \mathrm{~A}$

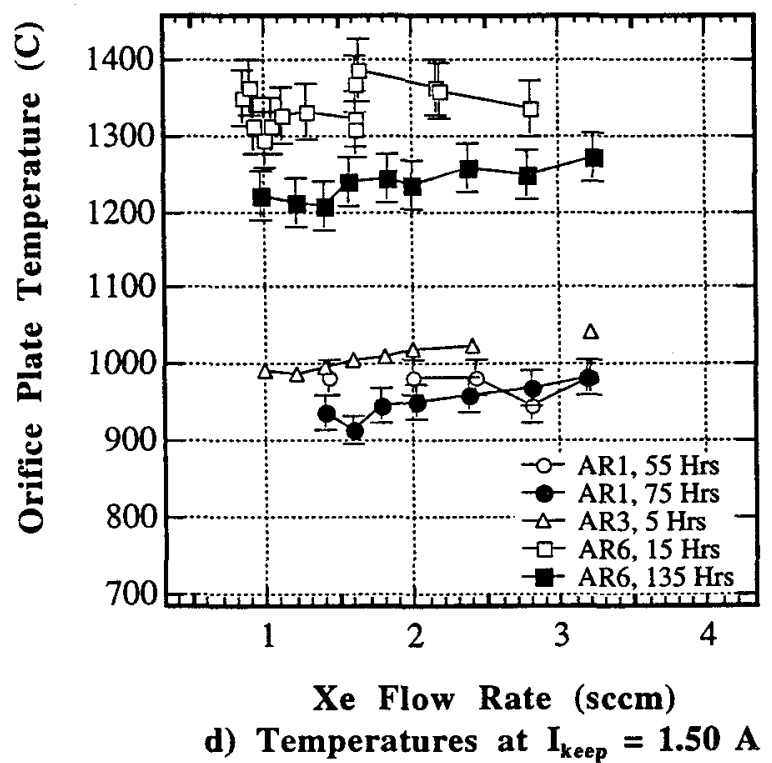

d) Temperatures at $I_{\text {keep }}=1.50 \mathrm{~A}$

Figure 7 - Orifice Plate Temperatures at Various Discharge Conditions

duration of these tests, it was anticipated that this cathode would eventually become entirely unstable at currents below 1.25 A. This situation illustrated the importance of the design of the thermal environment for low current hollow cathodes.

The unstable operation of AR1 at $0.75 \mathrm{~A}$ illustrates the need for a more detailed description for the energy transport in low current hollow cathodes. Other work by Domonkos, Gallimore and Patterson ${ }^{15}$ presents a thermographic investigation of low current hollow cathodes. Both the work presented here and in
Reference 15 are part of an ongoing project to develop an effective cathode thermal model that will facilitate optimization of hollow cathodes for low power applications.

\section{Acknowledgments}

This work was performed at the NASA Lewis Research Center under Grant No. NGT-3-52311. The authors greatly appreciate the technical assistance provided by Michael Pastel, Ralph Jacko, Robert Roman, Tim Sarver-Verhey, and George Soulas. 


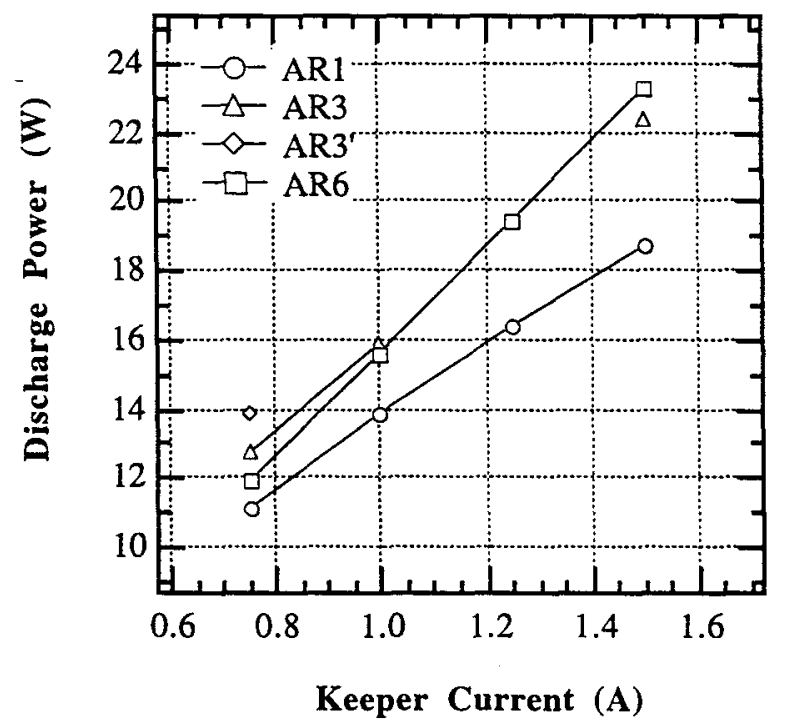

Figure 8 - Power Consumption at $2.4 \mathrm{sccm}$ of Xe

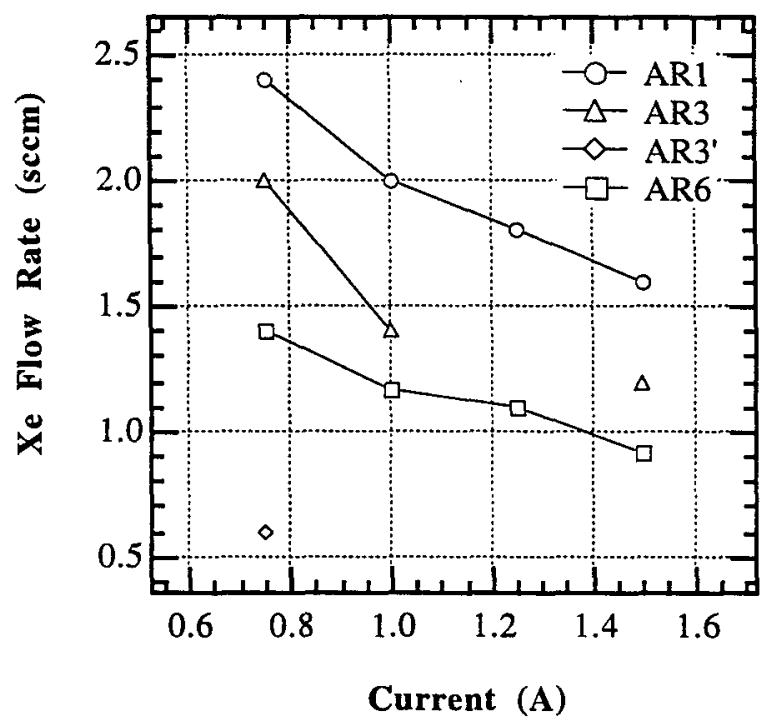

Figure 9 - Flow Rate at the Onset of Plume Mode

\section{References}

${ }^{1}$ Patterson, M. J. and Oleson, S. R., "Low Power Ion Propulsion for Small Spacecraft," AIAA Paper No. 97-3060, 33rd AIAA Joint Propulsion Conference, Seattle, WA, July, 1997.
${ }^{2}$ Patterson, M. J., Grisnik, S. P., and Soulas, G. C., "Scaling of Ion Thrusters to Low Power," IEPC Paper No. 97-098, 25th International Electric Propulsion Conference, Cleveland, OH, Aug. 1997. ${ }^{3}$ Mirtich, M. J. and Kerslake, W. R., "Long Lifetime Hollow Cathodes for 30-cm Mercury Ion Thrusters," AIAA Paper No. 76-985, AIAA Intemational Electric Propulsion Conference, Key Biscayne, FL, Nov. 1976.

${ }^{4}$ Rawlin, V. K. and Pawlik, E.V., "A Mercury Plasma-Bridge Neutralizer," Journal of Spacecraft and Rockets, Vol. 5, No. 7, July 1968, pp. 814-820.

${ }^{5}$ Mandell, M. J. and Katz, I., "Theory of Hollow Cathode Operation in Spot and Plume Modes," AIAA Paper No. 94-3134, 30th AIAA Joint Propulsion Conference, Indianapolis, IN, June 1994.

${ }^{6}$ Siegfried, D. E. and Wilbur, P. J., "A Model for Mercury Orificed Hollow Cathodes: Theory and Experiment," AIAA Journal, Vol. 22, No. 10, Oct. 1984, pp. 1405-1412.

${ }^{7}$ Salhi, A., Theoretical and Experimental Studies of Orificed, Hollow Cathode Operation, Ph.D. Dissertation, 1993.

${ }^{8}$ Rehn, L. and Kaufman, H. R., "Correlation of Inert Gas Hollow Cathode Performance," AIAA Paper No. 78-707, 13th International Electric Propulsion Conference, San Diego, CA, April 1978.

9 Rawlin, V. K. and Kerslake, W. R., "SERT II: Durability of the Hollow Cathode and Future Applications of Hollow Cathodes," Journal of Spacecraft and Rockets, Vol. 7, No. 1, Jan. 1970, pp. 14-20.

${ }^{10}$ Patterson, M. J., Verhey, T. R., Soulas, G., and Zakany, J., "Space Station Cathode Design, Performance, and Operating Specifications," IEPC Paper No. 97-170, 25th International Electric Propulsion Conference, Cleveland, OH, Aug. 1997.

"Sarver-Verhey, T. R., "Extended Test of a Xenon Hollow Cathode for a Space Plasma Contactor," NASA Contractor Report 195402, Nov. 1994.

12 Ramalingam, M. L. and Jacobson, D. L., "An Accurate Method for the Determination of Normal Spectral Emissivities of Refractory Alloys," AIAA 
Paper No. 87-0321, AIAA 25th Aerospace Sciences

Meeting, Reno, NV, Jan. 1987.

${ }^{13}$ McGee, T. D., Principles And Methods of

Temperature Measurement, John Wiley \& Sons, Inc., New York, 1988.

${ }^{14} \mathrm{Katz}, \mathrm{I}$. and Patterson, M. J., "Optimizing Plasma Contactors for Electrodynamic Tether Missions," Tether Technology Interchange, Huntsville, AL, Sept. 1997.

15 Domonkos, M. T., Gallimore, A. D., and Patterson, M. J., "Thermographic Investigation of 3.2-mm-Diameter Orificed Hollow Cathodes," AIAA Paper No. 98-3793, 34th AIAA/ASME/SAE/ASEE Joint Propulsion Conference and Exhibit, Cleveland, OH, July 1998. 